\title{
MANAGEMENT OF ENDOCRINE DISEASE Suicide risk in patients with diabetes: a systematic review and meta-analysis
}

\author{
Bin Wang, Xiaofei An, Xiaohong Shi and Jin-an Zhang \\ Department of Endocrinology, Jinshan Hospital of Fudan University, Shanghai, China
}

Correspondence

should be addressed

to J Zhang

Email

zhangjinan@hotmail.com

\begin{abstract}
Background: Previous studies investigating the risk of suicide in diabetes patients reported controversial findings. We did a systematic review and meta-analysis to comprehensively estimate the risk and incidence rate of suicide in diabetic patients.

Methods: PubMed, EMBASE and PsycINFO were searched for eligible studies. Random-effects meta-analysis was used to calculate the relative risk (RR) and the incidence rate of suicide in diabetes patients. We also calculated the proportion of deaths attributable to suicide among diabetes patients.

Results: 54 studies were finally included, including 28 studies on the suicide risk associated with diabetes, 47 studies on the incidence rate of suicide and 45 studies on the proportion of deaths attributable to suicide. Meta-analysis showed that diabetes could significantly increase the risk of suicide (RR=1.56; $95 \% \mathrm{Cl}: 1.29-1.89 ; P<0.001)$. Subgroup analysis showed that the RR of suicide associated with type 1 diabetes was 2.25 (95\% Cl: $1.50-3.38 ; P<0.001)$. The pooled incidence rate of suicide in patients with diabetes was 2.35 per 10000 person-years (95\% Cl: 1.51-3.64). The pooled proportions of long-term deaths attributable to suicide in type 1 diabetes patients and type 2 diabetes patients were $7.7 \%(95 \% \mathrm{Cl}: 6.0-9.8)$ and $1.3 \%(95 \% \mathrm{Cl}: 0.6-2.6)$, respectively.

Conclusion: This meta-analysis suggests that diabetes can significantly increase the risk of suicide. Suicide has an obvious contribution to mortality in diabetic patients, especially among type 1 diabetes patients. Effective strategies to decrease suicide risk and improve mental health outcomes in diabetes patients are needed.
\end{abstract}

\section{Introduction}

Suicide is one common cause of death with almost 1 million people dying from suicide worldwide each year, and it is a serious problem for global public health (1). Identification of risk factors of suicide is very important for the development of effective prevention strategies for suicide (2). Diabetes is also a public health issue worldwide and its global pandemic is still increasing obviously (3, 4). There are over 400 million people suffering from diabetes worldwide, and its prevalence is still increasing every year (4). Diabetes is also associated with increased risks of many subsequent diseases, such as cardiovascular diseases, cancers and chronic kidney disease $(5,6,7,8)$.

Mental diseases are common among patients with diabetes, such as depression and suicidal ideation, but mental health is still a neglected comorbidity in patients with diabetes $(9,10,11)$. Recent studies have suggested possibly increased risk of externally caused death such as suicide in patients with diabetes $(12,13,14,15)$. However, the risk of suicide associated with diabetes has not received enough attention. To date, it is still unclear www.eje-online.org DOI: 10.1530/EJE-16-0952
() 2017 European Society of Endocrinology Printed in Great Britain
Published by Bioscientifica Ltd. 
whether diabetes can result in increased risk of suicide. There was also lack of a comprehensive estimation of suicide risk associated with diabetes. Therefore, to provide a comprehensive estimation of the risk of suicide in diabetes patients, we carried out a systematic review and meta-analysis of published studies. In this meta-analysis, to appropriately evaluate the risk of suicide in diabetes patients, we investigated the risk of suicide associated with diabetes, the incidence rate of suicide in diabetic patients and the contribution of suicide to mortality in diabetic patients. This systematic review was registered at PROSPERO (CRD42016039709).

\section{Methods}

\section{Search strategy and selection criteria}

PubMed, EMBASE and PsycINFO were searched to identify eligible studies. Databases were searched from January 1980 to October 15, 2016. We updated the literature search in PubMed on February 16, 2017. We used keywords and MeSH searches with the combination of the following terms: (suicide OR suicides OR suicidal OR suicidality) AND (diabetes OR diabetic OR T1DM or T2DM OR NIDDM OR IDDM). Language restriction was not used. The reference lists of relevant articles or reviews were also retrieved to for more eligible studies.

The following predefined inclusion criteria were used: (a) cohort studies; (b) for studies assessing the risk of suicide associated with diabetes, the exposure of interest was diabetes and for studies on the rate of suicide, diabetes patients were the population of interest; (c) studies recruiting either type 1 diabetes mellitus (T1DM) patients or type 2 diabetes mellitus (T2DM) patients, or studies mixing T1DM patients and T2DM patients together were all considered eligible; (d) the outcomes of interest were the incidence rate of suicide, the proportion of deaths attributable to suicide and the risk estimates of suicide associated with diabetes, such as standardized mortality ratio (SMR), hazard ratio (HR), relative risk (RR) and odds ratio (OR); (e) reporting data on the outcomes of interests. Since a few studies did not report the risk or the incidence rate of suicide in either T1DM or T2DM patients separately, but reported outcomes in a population, which mixed T1DM patients and T2DM patients together, we thus firstly assessed the risk of suicide in diabetes patients regardless of its types. However, to make it more appropriate, we would then stratified the studies by the types of diabetes and evaluated the risk or the incidence rate of suicide in patients with either T1DM or T2DM separately. Studies reporting suicide attempts or suicidal ideation were excluded.

\section{Data extraction and quality assessment}

A standardized extraction form was used, and disagreements were resolved by discussion. Data were independently extracted by two reviewers from the fulltexts of included studies. Study characteristics, such as first author's name, number of participants, demographic characteristics, the number of person-years, incident cases of suicide, time of follow-up, completeness of follow-up, method of standardization of SMR and risk estimates (SMR, HR, RR or OR), were all extracted. Newcastle-Ottawa Scale was utilized to evaluate the bias risk of observational studies with comparison groups, which assessed studies on three domains including the selection of participants, the comparability of exposure group and non-exposed group, and the ascertainment of the outcomes (16). The comparability was mainly assessed by the adjustment for confounding factors or the standardization of SMRs. Four, two and three stars were scored for those three domains, respectively. Studies with less than 6 stars were deemed to have high risk of bias, and studies with one star for the selection of participants or outcome ascertainment, or zero for any domain were all deemed to have high risk of bias $(17,18)$. For studies without a comparison group, which reported data on the incidence rate of suicide or the proportion of deaths attributable to suicide among diabetes patients, the risk of bias was assessed by a modified version of Newcastle-Ottawa scale proposed by Rotenstein et al. (19). The modified scale assessed the risk of bias of those studies without a comparison group on five items including representativeness of participants, sample size, comparability between respondents and nonrespondents, ascertainment of suicide and thoroughness of descriptive statistics. One point was scored for each item in the modified bias scoring scale, and studies were judged to have low risk of bias $(\geq 3$ points) or high risk of bias ( $<3$ points).

\section{Statistical analysis}

Meta-analyses were performed on the incidence rate of suicide, the risk estimate of suicide associated with diabetes and the proportion of deaths attributable to suicide, respectively. Because the incidence of suicide in diabetes patients was relatively low, OR and HR were approximately close to RR and were assumed to be the 
same measure and a common estimate of RR, and this strategy had been used in many published meta-analyses of observational studies $(20,21,22,23)$. Besides, SMR was in line regarded as one form of RR in epidemiological researches and was thus conventionally used as the same measure of RR in the present meta-analysis. As the results were presented separately for men and women in some studies, we firstly obtained a within-study summary RR using a fixed-effect meta-analysis. The pooled estimates with $95 \%$ confidence intervals (95\% CIs) were calculated using a random-effects model (24). This meta-analysis used both the $I^{2}$ statistic and the Cochran's Q statistic to evaluate the heterogeneity $(25,26) . I^{2}$ more than $50 \%$ indicated substantial heterogeneity among included studies. The proportion of deaths attributable to suicide was converted by the method of Freeman-Tukey double arcsine transformation before data synthesis, and then was back-transformed to the original pattern, and it was calculated using the METARATE command in the 'meta' package for $\mathrm{R}$. The incidence rates of suicide were pooled using the 'metan' module of STATA. The commands above in detail were shown in Supplementary Table 1 (see section on supplementary data given at the end of this article). Sensitivity analysis was performed by excluding studies with high risk of bias. The estimates were also stratified by gender and types of diabetes. Publication bias was evaluated by funnel plot and Egger's test (27). Metaanalysis was carried out using Stata (version 12, Stata Corp.) and R Studio (version 3.0.2). A $P$ value less than 0.05 suggested statistical significance.

\section{Results}

\section{Study selection and characteristics}

1391 unique records were identified from literature search (Fig. 1). 127 articles with full-texts were screened and 54 studies were finally included into the meta-analysis (12, $13,14,15,28,29,30,31,32,33,34,35,36,37,38,39,40$, $41,42,43,44,45,46,47,48,49,50,51,52,53,54,55,56$, $57,58,59,60,61,62,63,64,65,66,67,68,69,70,71,72$, $73,74,75,76,77)$. There were 28 studies on the suicide risk associated with diabetes $(12,13,14,15,28,29,31,32$, $33,34,36,38,40,41,42,43,46,47,48,50,52,54,56,60$, $62,63,70,76), 47$ studies on the incidence rate of suicide in patients with diabetes $(12,14,15,28,30,31,33,35,36$, $37,39,40,41,42,43,44,45,46,47,48,49,50,51,52,53$, $54,55,56,57,58,59,60,61,62,63,64,65,66,67,68,70$, $71,73,74,75,76,77)$ and 45 studies on the proportion of deaths attributable to suicide in patients with diabetes

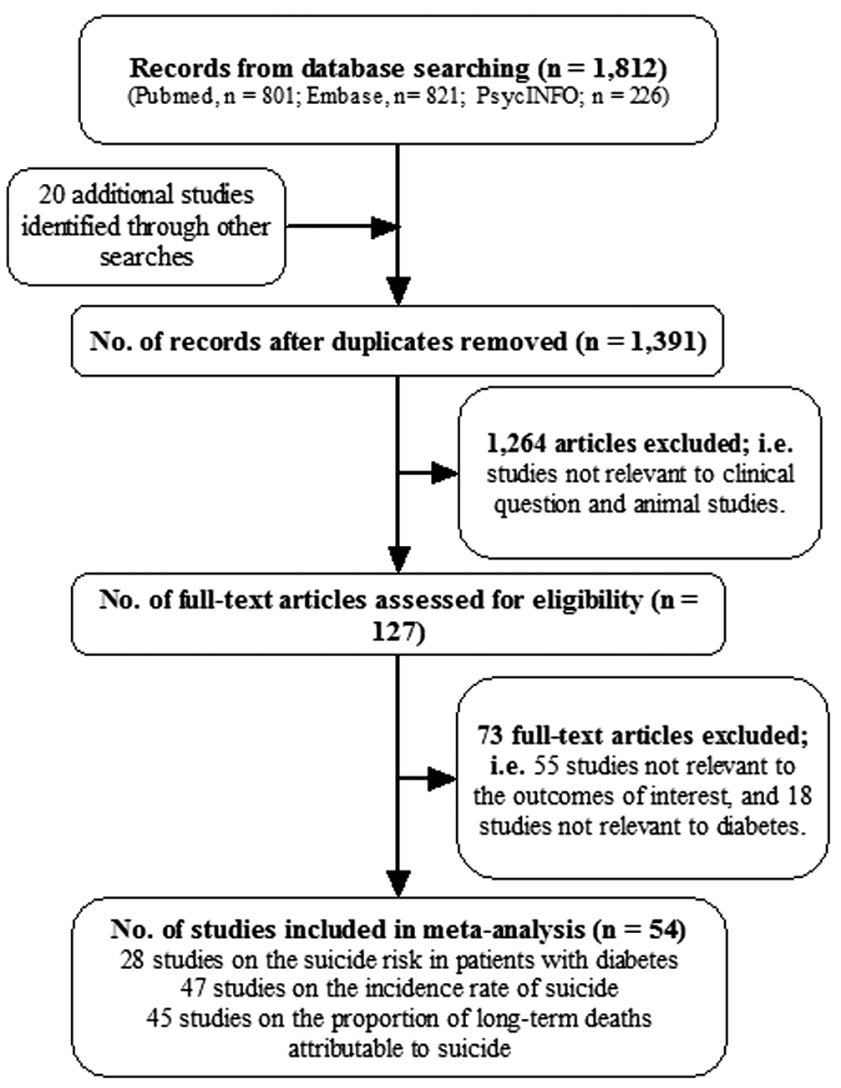

Figure 1

Flow chart of study selection in the meta-analysis.

$(12,14,15,28,30,31,33,35,36,37,39,40,41,42,43$, $44,45,46,47,48,49,50,51,52,53,54,55,56,57,58$, $59,60,61,62,63,64,65,66,67,68,69,70,71,72,73$, $74,75,76,77)$.

Table 1 described the main characteristics of those 28 studies on the suicide risk associated with diabetes (Table 1). Most studies were from North America and Europe, and all studies were published in English (Table 1). The mean or median time of follow-up ranged from 4.4 years to 28.7 years (Table 1 ). 14 studies reported SMRs of suicide in patients with diabetes, 6 studies reported HRs of suicide associated with diabetes and the other 8 studies reported RRs of suicide associated with diabetes (Table 1). 13 studies mixed T1DM patients and T2DM together and did not assess the risk of suicide in T1DM patients and T2DM patients separately (Table 1 ). Among those 28 studies, 11 studies reported data on risk estimates of suicide associated with T1DM, and 7 studies reported data on risk estimates of suicide associated with T2DM. According to the Newcastle-Ottawa scale, 24 studies had low risk of bias, while the other 4 studies had high 


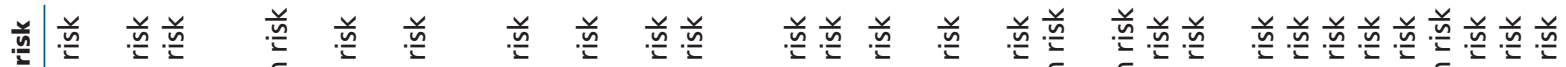
恶
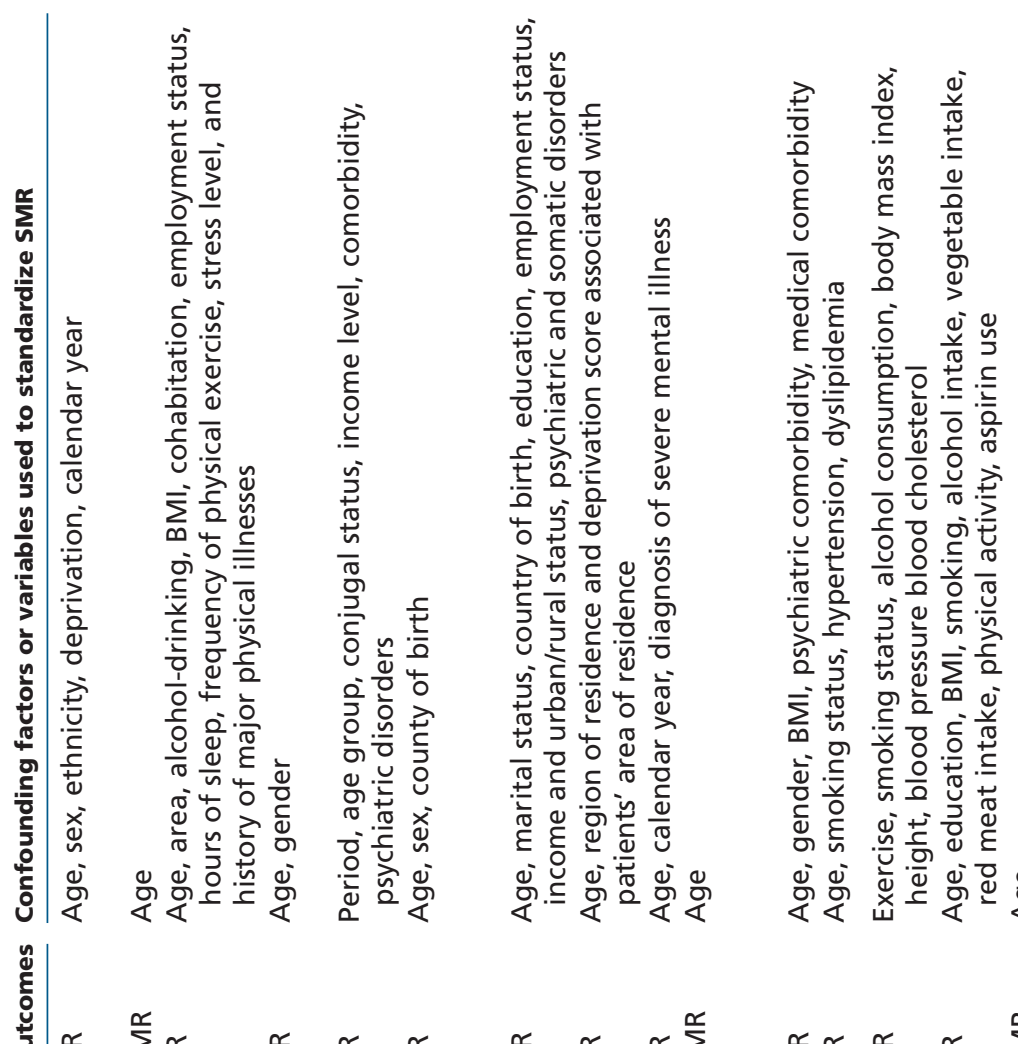

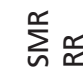

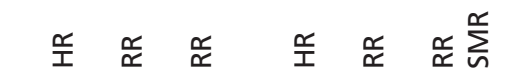

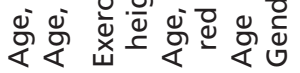

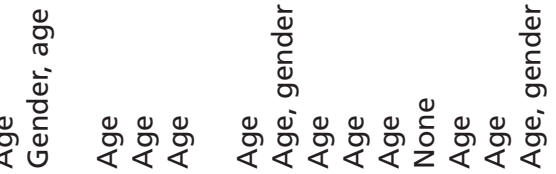

莺|

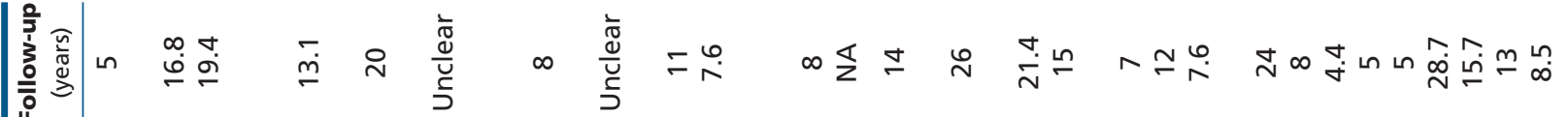


risk of bias (Table 1). The scores for each term were shown in detail in Supplementary Table 2. Table 2 described the main characteristics of 47 studies on the incidence rate of suicide in diabetic patients (Table 2). According to the modified version of Newcastle-Ottawa scale, 37 studies had low risk of bias, while the other 10 studies had high risk of bias, which was shown in detail in Supplementary Table 3. Table 3 described the main characteristics of 45 studies on the proportion of deaths attributable to suicide in patients with diabetic patients (Table 3). According to the modified version of Newcastle-Ottawa scale, 36 studies had low risk of bias, while the other 9 studies had high risk of bias, which was shown in detail in Supplementary Table 4.

\section{Meta-analysis}

Meta-analysis of 28 studies reporting risk estimates of suicide associated with diabetes showed that diabetes could significantly increase the risk of suicide $(\mathrm{RR}=1.56$; 95\% CI: 1.29-1.89; $P<0.001, I^{2}=93.2 \%$ ) (Fig. 2). After excluding studies with high risk of bias, there was still an obvious association between diabetes and increased risk of suicide $(\mathrm{RR}=1.56 ; 95 \% \mathrm{CI}: 1.27-1.91 ; P<0.001$, $I^{2}=94.3 \%$ ). Subgroup analysis by gender showed that diabetes was significantly associated with increased risk of suicide in both men $(\mathrm{RR}=1.39$; 95\% CI: $1.23-$ $\left.1.57 ; P<0.001, I^{2}=54.6 \%\right)$ and women $(\mathrm{RR}=1.36 ; 95 \%$ CI: $\left.1.10-1.69 ; P=0.004, I^{2}=63.7 \%\right)$. Subgroup analysis by types of diabetes showed that the RR of suicide associated with T1DM was 2.25 (95\% CI: 1.50-3.38; $P<0.001, I^{2}=69.3 \%$ ) (Fig. 3). However, there was a possible association between T2DM and increased risk of suicide $(\mathrm{RR}=1.65,95 \% \mathrm{CI}$ : $0.95-2.85 ; P=0.07$, $I^{2}=95.0 \%$ ). There was no obvious risk of publication bias in the meta-analysis of 28 studies reporting risk estimates of suicide associated with diabetes $\left(P_{\text {Egger's test }}=0.48\right)$.

Meta-analysis of 47 studies on the incidence rate of suicide showed that the pooled incidence rate of suicide in patients with diabetes was 2.35 per 10000 person-years (95\% CI: 1.51-3.64; $I^{2}=98.8 \%$ ). After excluding studies with high risk of bias, the pooled incidence rate of suicide in patients with diabetes was 1.81 per 10000 person-years (95\% CI: $1.13-2.90 ; I^{2}=99.0 \%$ ). Subgroup analysis by types of diabetes showed that the pooled incidence rate of suicide in T1DM and T2DM patients was 2.25 per 10000 person-years (95\% CI: $1.66-3.05 ; I^{2}=76.5 \%$ ) and 2.56 per 10000 person-years (95\% CI: $1.56-4.19 ; I^{2}=90.4 \%$ ), respectively. Subgroup analysis by gender showed that the pooled incidence rates of suicide in male diabetic patients and female diabetic patients were 2.34 per 10000 personyears (95\% CI: $1.06-5.17 ; I^{2}=99.3 \%$ ) and 0.94 per 10000 person-years (95\% CI: 0.38-2.30; $I^{2}=98.5 \%$ ) respectively.

Meta-analysis of 45 studies on the proportion of deaths attributable to suicide in diabetes patients showed that the pooled proportion was 3.5\% (95\% CI: 2.6-4.8; $\left.I^{2}=97 \%\right)$. After excluding studies with high risk of bias, the pooled proportion of deaths attributable to suicide in diabetes patients was $3.5 \%$ (95\% CI: $2.5-4.8 ; I^{2}=98 \%$ ). Subgroup analysis by types of diabetes showed that the pooled proportions in T1DM patients and T2DM patients were 7.7\% (95\% CI: 6.0-9.8; $\left.I^{2}=67 \%\right)$ and $1.3 \%$ (95\% CI: 0.6-2.6; $I^{2}=94 \%$ ) respectively (Fig. 4). Subgroup analysis by gender showed that the pooled proportions of longterm deaths attributable to suicide in male diabetic patients and female diabetic patients were 2.9\% (95\% CI: $\left.1.9-4.5 ; I^{2}=98 \%\right)$ and $1.3 \%$ (95\% CI: $0.8-2.2$; $\left.I^{2}=97 \%\right)$ respectively.

\section{Discussion}

Both diabetes and suicide are complex global health problems, and an accurate estimate of suicide risk associated with diabetes is crucial. However, the risk of suicide in diabetic patients is still not well understood and has not been comprehensively assessed. We therefore did a systematic review and meta-analysis to comprehensively estimate the risk and the incidence rate of suicide in diabetes patients. Our study is the first systematic review and meta-analysis investigating the risk of suicide in patients with diabetes. 54 studies were finally included, including 28 studies on the suicide risk in patients with diabetes, 47 studies on the incidence rate of suicide in patients with diabetes and 45 studies on the proportion of deaths attributable to suicide in diabetes patients. The findings suggested that diabetes was significantly associated with increased risk of suicide ( $\mathrm{RR}=1.56$; 95\% CI: 1.29-1.89; $P<0.001$ ) (Fig. 2). The association was more profound in T1DM patients, and the RR of suicide associated with T1DM was 2.25 (95\% CI: 1.50-3.38; $P<0.001$ ). The pooled incidence rate of suicide in patients with diabetes was 2.35 per 10000 person-years (95\% CI: $1.51-3.64)$. The pooled proportions of deaths attributable to suicide in T1DM patients and T2DM patients were 7.7\% (95\% CI: 6.09.8) and 1.3\% (95\% CI: 0.6-2.6), respectively (Fig. 4). 
Table 2 Characteristics of 47 cohort studies investigating the incidence rate of suicide in patients with diabetes.

\begin{tabular}{|c|c|c|c|}
\hline Study & Country & Type of diabetes & Participants, n \\
\hline (76) & UK & T2DM & 187968 \\
\hline (77) & Taiwan & Mixed & 92546 \\
\hline (28) & Norway & T1DM & 7871 \\
\hline (15) & Japan & Mixed & 4898 \\
\hline (14) & Australia & T2DM & 1413 \\
\hline (30) & USA & T1DM & 1441 \\
\hline (31) & Sweden & Mixed & 7140589 \\
\hline (33) & Denmark & Mixed & 4734703 \\
\hline (36) & Australia & T1DM & $\begin{array}{l}\text { 1309: T1DM; } 6451 \text { age- and } \\
\text { sex-matched controls }\end{array}$ \\
\hline (35) & USA & T2DM & 4128 \\
\hline (37) & Japan & T1DM & 1324 \\
\hline (39) & Finland & T1DM & 4174 \\
\hline (40) & Korea & T2DM & 42082 \\
\hline (41) & USA & Mixed & 52655 \\
\hline (42) & Finland & T1DM & 17306 \\
\hline (43) & Sweden & Mixed & 879 \\
\hline (44) & USA & T1DM & 1075 \\
\hline (45) & USA & T2DM & 4184 \\
\hline (46) & Taiwan & Mixed & 1792 \\
\hline (47) & UK & T1DM & 4246 \\
\hline (48) & 13 countries & T1DM & 28887 \\
\hline (49) & USA & T2DM & 123 \\
\hline (50) & Norway & T1DM & 1906 \\
\hline (51) & Sweden & T1DM/ T2DM & 6771 \\
\hline (52) & Sweden & T1DM & 10200 \\
\hline (53) & Italy & T1DM or T2DM & 31264 \\
\hline (54) & Taiwan & Mixed & 256036 \\
\hline (55) & Germany & T1DM & 3674 \\
\hline (56) & Sweden & Mixed & 4097 \\
\hline (57) & USA & T2DM & 710 \\
\hline (58) & UK & T1DM & 1854 \\
\hline (59) & France & T2DM & 237 \\
\hline (60) & Finland & T2DM & 11215 \\
\hline (61) & Austria & T1DM & 1185 \\
\hline (62) & Sweden & T1DM & 91 \\
\hline (63) & UK & Mixed & 5783 \\
\hline (64) & UK & T1DM & 845 \\
\hline (65) & Sweden & T1DM & 4919 \\
\hline (12) & Denmark & T1DM & 1682 \\
\hline (66) & USA & T2DM & 353 \\
\hline (67) & Sweden & T1DM or T2DM & 1467: T1DM; 334: T2DM \\
\hline (68) & UK & T1DM & 310 \\
\hline (71) & Norway & T1DM & 1908 \\
\hline (70) & USA & T1DM or T2DM & 1200: T1DM; 1772: T2DM \\
\hline (73) & Japan & Mixed & 62 \\
\hline (75) & UK & T1DM & 45 \\
\hline (74) & USA & Mixed & 21447 \\
\hline
\end{tabular}

\begin{tabular}{c}
$\begin{array}{c}\text { Follow-up } \\
\text { (years) }\end{array}$ \\
\hline 5 \\
12 \\
16.8 \\
19.4 \\
13.1 \\
27 \\
8 \\
11 \\
7.6
\end{tabular}

\begin{tabular}{c}
\hline Suicide \\
\hline 88 \\
327 \\
20 \\
41 \\
4 \\
7 \\
8721 \\
1013 \\
6
\end{tabular}

Bias risk

Low risk Low risk Low risk Low risk Low risk Low risk Low risk Low risk Low risk

$10 \quad 6 \quad$ Low risk

$35 \quad 7 \quad$ Low risk
9 Low risk $14 \quad 38$ Low risk $26 \quad 113$ Low risk $21.4 \quad 110 \quad$ Low risk $15 \quad 2$ High risk $32 \quad 8 \quad$ Low risk $4.4 \quad 4 \quad$ Low risk $7 \quad 2 \quad$ High risk $12 \quad 6 \quad$ Low risk $\begin{array}{lll}7.6 & 11 \quad \text { Low risk }\end{array}$ $4.3 \quad 1 \quad$ High risk $24 \quad 13 \quad$ Low risk $8.5 \quad 17 \quad$ Low risk $8 \quad 7 \quad$ Low risk 928 Low risk $4.4 \quad 361 \quad$ Low risk $10 \quad 22 \quad$ Low risk $5 \quad 10 \quad$ Low risk $22 \quad 2$ Low risk $9.3 \quad 1 \quad$ Low risk $5 \quad 2$ High risk $5 \quad 77 \quad$ Low risk $6 \quad 1 \quad$ High risk $28.7 \quad 2 \quad$ High risk $15.7 \quad 17 \quad$ High risk $17 \quad 2 \quad$ Low risk $\begin{array}{lll}7 & 1 & \text { Low risk }\end{array}$ $13 \quad 12 \quad$ Low risk $8 \quad 1 \quad$ Low risk $2.6 \quad 3 \quad$ Low risk 8 High risk $10 \quad 2 \quad$ Low risk $8.5 \quad 5 \quad$ Low risk 0.5-10 3 High risk $18 \quad 2$ High risk 26 Ligh risk

NA, not available; T1DM, type 1 diabetes mellitus; T2DM, type 2 diabetes mellitus.

The above findings suggest an obvious risk of suicide in patients with diabetes.

Diabetes is a chronic metabolic disease, and there are about 400 million people with diabetes worldwide $(4,5,78)$. This meta-analysis suggests that the incidence rate of suicide in patients with diabetes is 2.35 per 10000 person-years, which indicates that there are about 94000 completed suicides occurring in diabetes patients worldwide every year. In addition, the high proportion of deaths attributable to suicide in diabetes patients also shows a high risk of suicide in diabetes patients. 
Table 3 Characteristics of 45 cohort studies investigating the proportion of deaths attributable to suicide in patients with diabetes.

\begin{tabular}{|c|c|c|c|c|c|c|}
\hline Study & Country & $\begin{array}{l}\text { Type of } \\
\text { diabetes }\end{array}$ & Participants, $n$ & $\begin{array}{l}\text { Follow-up } \\
\text { (years) }\end{array}$ & $\begin{array}{c}\text { Number of all deaths } \\
\text { (suicide) }\end{array}$ & Bias risk \\
\hline (76) & UK & T2DM & 187968 & 5 & $40286(88)$ & Low risk \\
\hline (77) & Taiwan & Mixed & 92546 & 12 & 327 & Low risk \\
\hline (28) & Norway & T1DM & 7871 & 16.8 & $241(20)$ & Low risk \\
\hline (30) & USA & T1DM & 1441 & 27 & $107(7)$ & Low risk \\
\hline (33) & Denmark & Mixed & 4734703 & 11 & 55424 (1013) & Low risk \\
\hline (36) & Australia & T1DM & $\begin{array}{l}\text { 1309: T1DM; 6451: age- and } \\
\text { sex-matched controls }\end{array}$ & 7.6 & $20(6)$ & Low risk \\
\hline (35) & USA & T2DM & 4128 & 10 & $1217(6)$ & Low risk \\
\hline (37) & Japan & T1DM & 1324 & 35 & $223(7)$ & Low risk \\
\hline (39) & Finland & T1DM & 4174 & 9 & $455(6)$ & Low risk \\
\hline (41) & USA & Mixed & 52655 & 26 & 38559 (113) & Low risk \\
\hline (42) & Finland & T1DM & 17306 & 21.4 & $1338(110)$ & Low risk \\
\hline (43) & Sweden & Mixed & 879 & 15 & $29(2)$ & High risk \\
\hline (44) & USA & T1DM & 1075 & 32 & $279(8)$ & Low risk \\
\hline (45) & USA & T2DM & 4184 & 4.4 & $581(4)$ & Low risk \\
\hline (46) & Taiwan & Mixed & 1792 & 7 & $156(2)$ & High risk \\
\hline (47) & UK & T1DM & 4246 & 12 & $108(6)$ & Low risk \\
\hline (48) & 13 countries & T1DM & 28887 & 7.6 & $141(11)$ & Low risk \\
\hline (49) & USA & T2DM & 123 & 4.3 & $110(1)$ & High risk \\
\hline (50) & Norway & T1DM & 1906 & 24 & 103 (13) & Low risk \\
\hline (51) & Sweden & $\begin{array}{l}\text { T1DM/ } \\
\text { T2DM }\end{array}$ & 6771 & 8.5 & $120(17)$ & Low risk \\
\hline (52) & Sweden & T1DM & 10200 & 8 & $78(7)$ & Low risk \\
\hline (69) & UK & T1DM & Unclear & Unclear & $98(12)$ & Low risk \\
\hline (53) & Italy & $\begin{array}{l}\text { T1DM or } \\
\text { T2DM }\end{array}$ & 31264 & 9 & $6749(28)$ & Low risk \\
\hline (54) & Taiwan & Mixed & 256036 & 4.4 & $16015(361)$ & Low risk \\
\hline (55) & Germany & T1DM & 3674 & 10 & $251(22)$ & Low risk \\
\hline (56) & Sweden & Mixed & 4097 & 5 & $58(10)$ & Low risk \\
\hline (57) & USA & T2DM & 710 & 22 & $476(2)$ & Low risk \\
\hline (58) & UK & T1DM & 1854 & 9.3 & $26(1)$ & Low risk \\
\hline (59) & France & T2DM & 237 & 5 & $12(2)$ & High risk \\
\hline (60) & Finland & T2DM & 11215 & 5 & $11215(77)$ & Low risk \\
\hline (61) & Austria & T1DM & 1185 & 6 & $6(1)$ & High risk \\
\hline (62) & Sweden & T1DM & 91 & 28.7 & $12(2)$ & High risk \\
\hline (63) & UK & Mixed & 5783 & 15.7 & 3090 (17) & Low risk \\
\hline (64) & UK & T1DM & 845 & 17 & $44(2)$ & Low risk \\
\hline (65) & Sweden & T1DM & 4919 & 7 & $33(1)$ & Low risk \\
\hline (12) & Denmark & T1DM & 1682 & 13 & $168(12)$ & Low risk \\
\hline (66) & USA & T2DM & 353 & 8 & $67(1)$ & Low risk \\
\hline (67) & Sweden & $\begin{array}{l}\text { T1DM or } \\
\text { T2DM }\end{array}$ & 1467: T1DM; 334: T2DM & 2.6 & $10(3)$ & Low risk \\
\hline (68) & UK & T1DM & 310 & 8 & $7(1)$ & High risk \\
\hline (71) & Norway & T1DM & 1908 & 10 & $20(2)$ & Low risk \\
\hline (70) & USA & $\begin{array}{l}\text { T1DM or } \\
\text { T2DM }\end{array}$ & 1200: T1DM; 1772: T2DM & 8.5 & $1004(5)$ & Low risk \\
\hline (72) & USA & Mixed & Data from death certificates & Unclear & $233(5)$ & Low risk \\
\hline (73) & Japan & Mixed & 62 & $0.5-10$ & $25(3)$ & High risk \\
\hline (75) & UK & T1DM & 45 & 18 & $7(2)$ & High risk \\
\hline (74) & USA & Mixed & 21447 & 26 & $2474(44)$ & Low risk \\
\hline
\end{tabular}

NA, not available; T1DM, type 1 diabetes mellitus; T2DM, type 2 diabetes mellitus.

There are several possible explanations for the increased risk of suicide associated with diabetes. Depressive symptoms and suicidal ideation are common in patients with diabetes, both of which are associated with increased risk of completed suicide $(10,11,79)$. Apart from depression, other mental health problems are also common in diabetes patients, which can also lead to increased risk of suicide $(80,81)$. In addition, patients with diabetes usually have functional disabilities and comorbidity, and as a result of these impairments, the low quality of life 


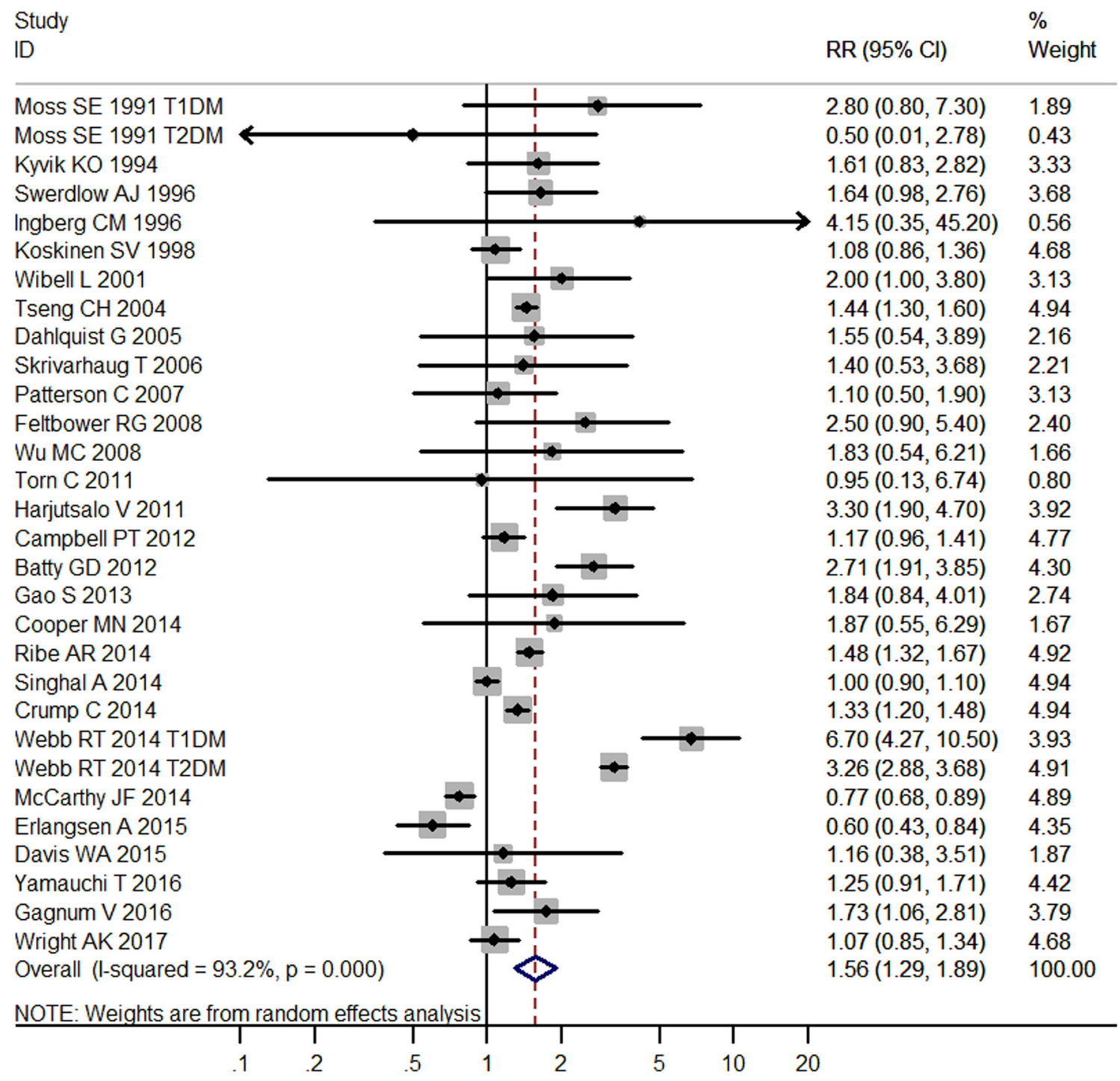

\section{Figure 2}

Meta-analysis showed that diabetes could obviously increase the risk of suicide. $95 \% \mathrm{Cl}, 95 \%$ confidence interval; RR, relative risk; T1DM, type 1 diabetes mellitus; T2DM, type 2 diabetes mellitus.

can further increase the severity of depression and the risk of suicide. However, the mechanism underlying the association between diabetes and suicide risk has not been well understood, and more studies are needed to further explore it.

This systematic review and meta-analysis has important implications for the management of diabetes. Given the increasing prevalence of diabetes worldwide and the increased risk of suicide associated with diabetes, it is urgent for us to develop effective solutions to decrease the suicide risk in diabetes patients, especially for T1DM patients. However, current guidelines for the treatment of diabetes provide few recommendations on the psychological monitoring and suicide prevention in diabetes patients. The findings from our meta-analysis suggest a great need to identify high-risk patients, and effective psychological support is necessary to decrease suicide risk among those patients $(1,2,82,83)$. Increased awareness of suicide risk associated with diabetes is also needed in clinical practice $(11,84)$. In addition, more studies are needed to develop effective strategies to decrease suicide risk and improve mental health outcomes in diabetes patients.

There is possibility of misclassification bias in the meta-analysis. Most included studies did not report whether they classified poisoning mortality into 


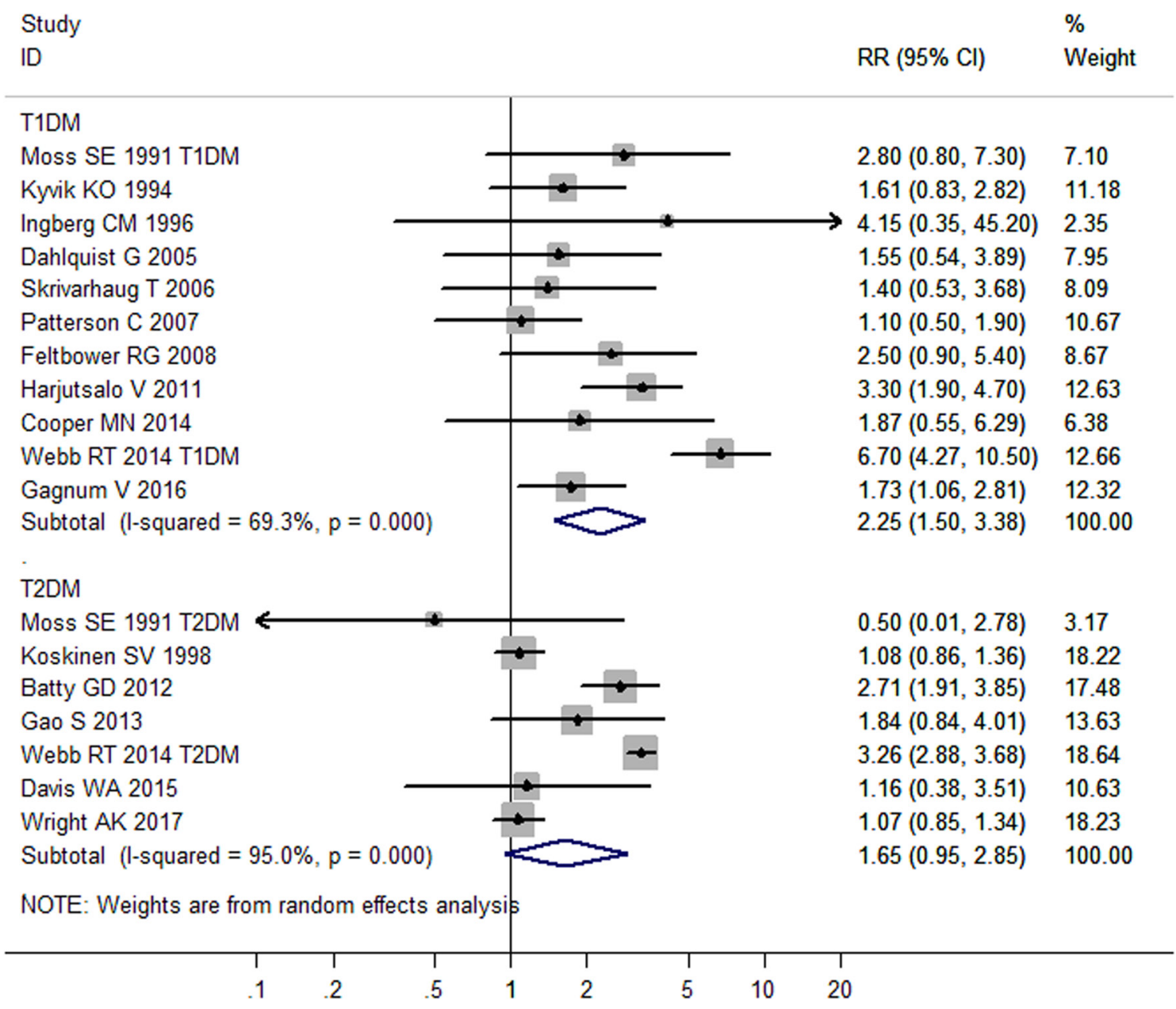

\section{Figure 3}

Forest plot in the subgroup analysis by types of diabetes. $95 \% \mathrm{Cl}, 95 \%$ confidence interval; RR, relative risk; T1DM, type 1 diabetes mellitus; T2DM, type 2 diabetes mellitus.

suicide, and some of those deaths listed as poisoning or drug overdose may be suicides, which may lead to an underestimation of the suicide risk in diabetes patients. The true proportion of deaths attributable to suicide in diabetes patients was also likely to be underestimated, because some suicide deaths may not be properly classified but were reported as poisoning or drug overdose in death certificates. Therefore, more population-based studies with high-quality data are urgently needed to estimate the magnitude of suicide risk in diabetes patients.

This meta-analysis had several other limitations. Firstly, there was obvious difference in the methodology across those included studies, which resulted in obvious between-study heterogeneity. Considering the obvious heterogeneity, the pooled estimates should be interpreted with caution. Secondly, the number of included studies was still relatively small in some subgroup analyses by types of diabetes or gender. More future studies with large number of participants are needed. Thirdly, deaths from suicide are usually difficult to ascertain. Misreporting of suicide deaths from families and relatives are also possible, which may result in imprecise estimates of suicide risk in diabetes patients (85). Finally, the outcomes from the subgroup analysis by types of diabetes showed that the risk of suicide associated with diabetes was likely to be more profound in T1DM patients, while there was a possible association between T2DM and increased risk of suicide ( $\mathrm{RR}=1.65,95 \% \mathrm{CI}$ : $0.95-2.85 ; P=0.07$ ). The nonsignificant association between T2DM and suicide risk may result from the small number of available studies, and more epidemiological studies are needed to further evaluate this association.

This meta-analysis suggests that diabetes can significantly increase risk of suicide. Suicide has an 


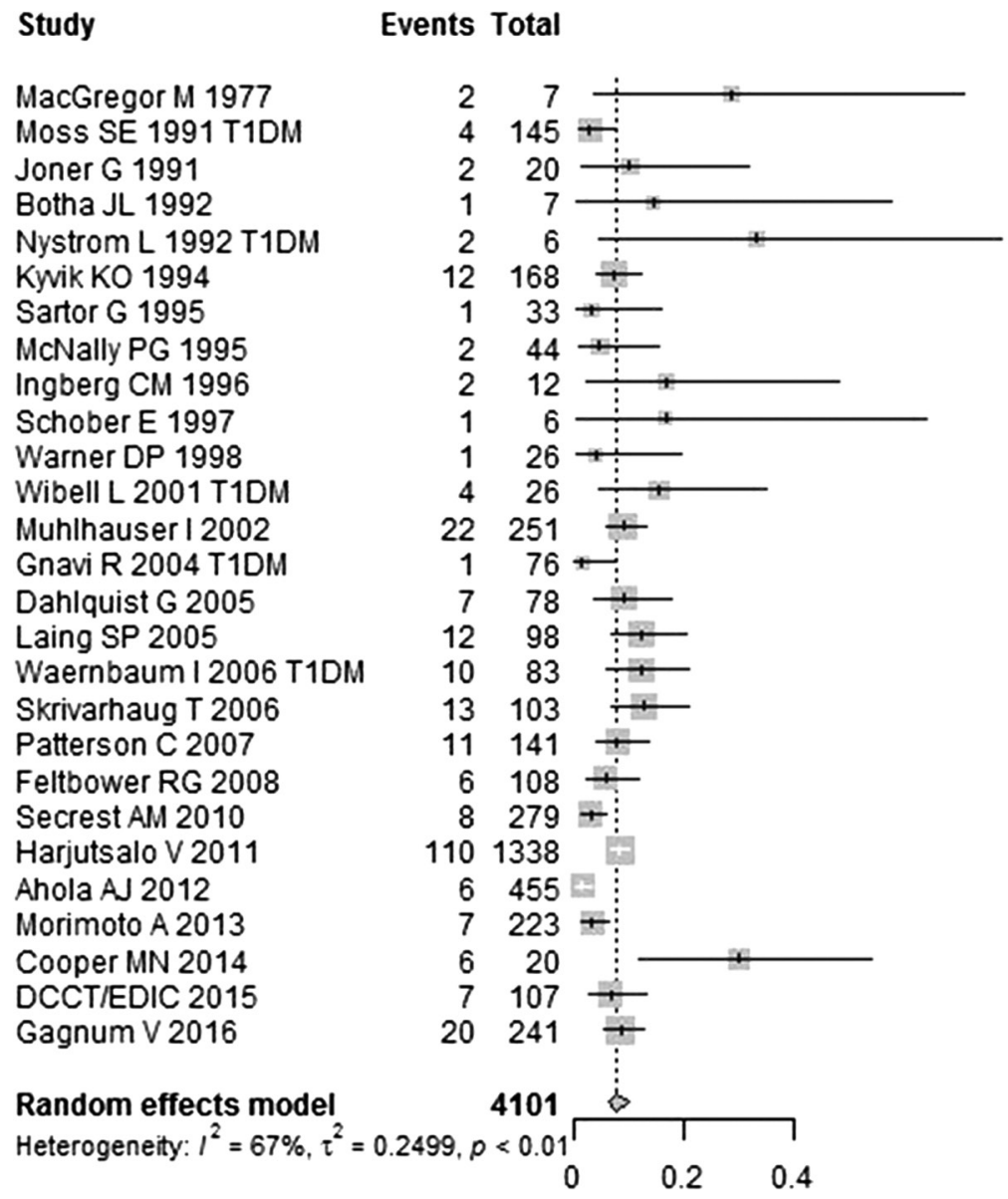

Proportion $\quad 95 \%-\mathrm{Cl}$ Weight

$\begin{array}{lll}0.286 & {[0.037 ; 0.710]} & 1.9 \% \\ 0.028 & {[0.008 ; 0.069]} & 3.6 \% \\ 0.100[0.012 ; 0.317] & 2.3 \% \\ 0.143[0.004 ; 0.579] & 1.3 \% \\ 0.333[0.043 ; 0.777] & 1.8 \% \\ 0.071[0.037 ; 0.121] & 5.3 \% \\ 0.030[0.001 ; 0.158] & 1.4 \% \\ 0.045[0.006 ; 0.155] & 2.3 \% \\ 0.167[0.021 ; 0.484] & 2.1 \% \\ 0.167[0.004 ; 0.641] & 1.3 \% \\ 0.038[0.001 ; 0.196] & 1.4 \% \\ 0.154[0.044 ; 0.349] & 3.3 \% \\ 0.088[0.056 ; 0.130] & 6.1 \% \\ 0.013[0.000 ; 0.071] & 1.4 \% \\ 0.090[0.037 ; 0.176] & 4.5 \% \\ 0.122[0.065 ; 0.204] & 5.3 \% \\ 0.120[0.059 ; 0.210] & 5.0 \% \\ 0.126[0.069 ; 0.206] & 5.4 \% \\ 0.078[0.040 ; 0.135] & 5.2 \% \\ 0.056[0.021 ; 0.117] & 4.3 \% \\ 0.029[0.012 ; 0.056] & 4.8 \% \\ 0.082[0.068 ; 0.098] & 7.0 \% \\ 0.013[0.005 ; 0.028] & 4.3 \% \\ 0.031[0.013 ; 0.064] & 4.6 \% \\ 0.300[0.119 ; 0.543] & 3.7 \% \\ 0.065[0.027 ; 0.130] & 4.5 \% \\ 0.083[0.051 ; 0.125] & 6.0 \% \\ & & \\ 0.077[0.060 ; 0.098] & 100.0 \%\end{array}$

\section{Figure 4}

Meta-analysis of data on the proportion of deaths attributable to suicide in T1DM patients. $95 \% \mathrm{Cl}, 95 \%$ confidence interval; T1DM, type 1 diabetes mellitus; T2DM, type 2 diabetes mellitus.

obvious contribution to mortality in diabetic patients, especially among T1DM patients. The findings from our meta-analysis suggest a great need to identify highrisk patients, and effective psychological support is necessary to decrease suicide risk among those patients. In addition, more epidemiological studies are needed to further evaluate the association between T2DM and suicide risk.

Supplementary data

This is linked to the online version of the paper at http://dx.doi.org/10.1530/ EJE-16-0952.

Declaration of interest

The authors declare that there is no conflict of interest that could be perceived as prejudicing the impartiality of this review.

\section{Funding}

The present work was supported by grants from the National Natural Science Foundation of China (81471004).

\section{References}

1 Turecki G \& Brent DA. Suicide and suicidal behaviour. Lancet 2016 387 1227-1239. (doi:10.1016/S0140-6736(15)00234-2)

2 Zalsman G, Hawton K, Wasserman D, van Heeringen K, Arensman E, Sarchiapone M, Carli V, Hoschl C, Barzilay R, Balazs J et al. Suicide prevention strategies revisited: 10-year systematic review. Lancet Psychiatry 20163 646-659. (doi:10.1016/S2215-0366(16)30030-X)

3 Menke A, Casagrande S, Geiss L \& Cowie CC. Prevalence of and trends in diabetes among adults in the United States, 1988-2012. JAMA 2015314 1021-1029. (doi:10.1001/jama.2015.10029)

4 NCD Risk Factor Collaboration (NCD-RisC). Worldwide trends in diabetes since 1980: a pooled analysis of 751 population-based studies with 4.4 million participants. Lancet 2016387 1513-1530. (doi:10.1016/s0140-6736(16)00618-8)

5 Pournaras DJ \& le Roux CW. Type 2 diabetes: multimodal treatment of a complex disease. Lancet 2015386 936-937. (doi:10.1016/S01406736(15)00132-4) 
6 Tancredi M, Rosengren A, Svensson AM, Kosiborod M, Pivodic A, Gudbjornsdottir S, Wedel H, Clements M, Dahlqvist S \& Lind M. Excess mortality among persons with type 2 diabetes. New England Journal of Medicine 2015373 1720-1732. (doi:10.1056/ nejmoa1504347)

7 Brownrigg JR, Hughes CO, Burleigh D, Karthikesalingam A, Patterson BO, Holt PJ, Thompson MM, de Lusignan S, Ray KK \& Hinchliffe RJ. Microvascular disease and risk of cardiovascular events among individuals with type 2 diabetes: a population-level cohort study. Lancet Diabetes and Endocrinology 20164 588-597. (doi:10.1016/ S2213-8587(16)30057-2)

8 Huo X, Gao L, Guo L, Xu W, Wang W, Zhi X, Li L, Ren Y, Qi X, Sun $\mathrm{Z}$ et al. Risk of non-fatal cardiovascular diseases in early-onset versus late-onset type 2 diabetes in China: a cross-sectional study. Lancet Diabetes and Endocrinology 20164 115-124. (doi:10.1016/S22138587(15)00508-2)

9 Handley TE, Ventura AD, Browne JL, Rich J, Attia JR, Reddy P, Pouwer F \& Speight J. Suicidal ideation reported by adults with type 1 or type 2 diabetes: results from diabetes MILES-Australia. Diabetic Medicine 201633 1582-1589. (doi: 10.1111/dme.13022)

10 Petrak F, Baumeister H, Skinner TC, Brown A \& Holt RI. Depression and diabetes: treatment and health-care delivery. Lancet Diabetes and Endocrinology 20153 472-485. (doi:10.1016/S22138587(15)00045-5)

11 The Lancet Diabetes Endocrinology. Poor mental health in diabetes: still a neglected comorbidity. Lancet Diabetes and Endocrinology 20153 393. (doi:10.1016/s2213-8587(15)00144-8)

12 Kyvik KO, Stenager EN, Green A \& Svendsen A. Suicides in men with IDDM. Diabetes Care 199417 210-212. (doi:10.2337/diacare.17.3.210)

13 Webb RT, Lichtenstein P, Dahlin M, Kapur N, Ludvigsson JF \& Runeson B. Unnatural deaths in a national cohort of people diagnosed with diabetes. Diabetes Care 201437 2276-2283. (doi:10.2337/dc14-0005)

14 Davis WA, Starkstein SE, Bruce DG \& Davis TM. Risk of suicide in Australian adults with diabetes: the Fremantle Diabetes Study. Internal Medicine Journal 201545 976-980. (doi:10.1111/imj.12853)

15 Yamauchi T, Inagaki M, Yonemoto N, Iwasaki M, Akechi T, Sawada N, Iso H, Noda M \& Tsugane S. History of diabetes and risk of suicide and accidental death in Japan: the Japan Public Health Centre-based Prospective Study, 1990-2012. Diabetes and Metabolism 201642 184-191. (doi:10.1016/j.diabet.2015.11.008)

16 Wells G, Shea B, O'connell D, Peterson J, Welch V, Losos M \& Tugwell P. The Newcastle-Ottawa Scale (NOS) for Assessing the Quality of Nonrandomised Studies in Meta-Analyses. Ottawa Health Research Institute, 2015. (Available at: http://www.ohri.ca/programs/clinical_ epidemiology/oxford.asp)

17 Viale L, Allotey J, Cheong-See F, Arroyo-Manzano D, McCorry D, Bagary M, Mignini L, Khan KS, Zamora J \& Thangaratinam S. Epilepsy in pregnancy and reproductive outcomes: a systematic review and meta-analysis. Lancet 2015386 1845-1852. (doi:10.1016/S01406736(15)00045-8.)

18 Sobhy S, Zamora J, Dharmarajah K, Arroyo-Manzano D, Wilson M, Navaratnarajah R, Coomarasamy A, Khan KS \& Thangaratinam $\mathrm{S}$. Anaesthesia-related maternal mortality in low-income and middle-income countries: a systematic review and meta-analysis. Lancet Global Health 20164 e320-e327. (doi:10.1016/S2214109X(16)30003-1)

19 Rotenstein LS, Ramos MA, Torre M, Segal JB, Peluso MJ, Guille C, Sen S \& Mata DA. Prevalence of depression, depressive symptoms, and suicidal ideation among medical students: a systematic review and meta-analysis. JAMA 2016316 2214-2236. (doi:10.1001/ jama.2016.17324)

20 Kivimaki M, Jokela M, Nyberg ST, Singh-Manoux A, Fransson EI, Alfredsson L, Bjorner JB, Borritz M, Burr H, Casini A et al. Long working hours and risk of coronary heart disease and stroke: a systematic review and meta-analysis of published and unpublished data for 603,838 individuals. Lancet 2015386 1739-1746. (doi:10.1016/S0140-6736(15)60295-1.)

21 Kivimaki M, Virtanen M, Kawachi I, Nyberg ST, Alfredsson L, Batty GD, Bjorner JB, Borritz M, Brunner EJ, Burr $\mathrm{H}$ et al. Long working hours, socioeconomic status, and the risk of incident type 2 diabetes: a meta-analysis of published and unpublished data from 222 120 individuals. Lancet Diabetes and Endocrinology 20153 27-34. (doi:10.1016/S2213-8587(14)70178-0)

22 Cornfield J. A method of estimating comparative rates from clinical data; applications to cancer of the lung, breast, and cervix. Journal of the National Cancer Institute 195111 1269-1275.

23 Kunutsor SK, Seidu S \& Khunti K. Statins and primary prevention of venous thromboembolism: a systematic review and metaanalysis. Lancet Haematology 20174 e83-e93. (doi:10.1016/S23523026(16)30184-3)

24 DerSimonian R \& Laird N. Meta-analysis in clinical trials. Controlled Clinical Trials 19867 177-188. (doi:10.1016/0197-2456(86)90046-2)

25 Cochran WG. The combination of estimates from different experiments. Biometrics 195410 101-129. (doi:10.2307/3001666)

26 Higgins JP, Thompson SG, Deeks JJ \& Altman DG. Measuring inconsistency in meta-analyses. BMJ 2003327 557-560. (doi:10.1136/ bmj.327.7414.557)

27 Egger M, Davey Smith G, Schneider M \& Minder C. Bias in metaanalysis detected by a simple, graphical test. BMJ 1997315 629-634. (doi:10.1136/bmj.315.7109.629)

28 Gagnum V, Stene LC, Jenssen TG, Berteussen LM, Sandvik L, Joner G, Njolstad PR \& Skrivarhaug T. Causes of death in childhood-onset Type 1 diabetes: long-term follow-up. Diabetic Medicine 201734 56-63. (doi:10.1111/dme.13114)

29 Erlangsen A, Stenager E \& Conwell Y. Physical diseases as predictors of suicide in older adults: a nationwide, register-based cohort study. Social Psychiatry and Psychiatric Epidemiology 201550 1427-1439. (doi:10.1007/s00127-015-1051-0)

30 Orchard TJ, Nathan DM, Zinman B, Cleary P, Brillon D, Backlund JY \& Lachin JM. Association between 7 years of intensive treatment of type 1 diabetes and long-term mortality. JAMA $20153 \mathbf{3 1 3}$ 45-53. (doi:10.1001/jama.2014.16107)

31 Crump C, Sundquist K, Sundquist J \& Winkleby MA. Sociodemographic, psychiatric and somatic risk factors for suicide: a Swedish National Cohort Study. Psychological Medicine 201444 279-289. (doi:10.1017/S0033291713000810)

32 Singhal A, Ross J, Seminog O, Hawton K \& Goldacre MJ. Risk of self-harm and suicide in people with specific psychiatric and physical disorders: comparisons between disorders using English national record linkage. Journal of the Royal Society of Medicine $2014 \mathbf{1 0 7}$ 194-204. (doi:10.1177/0141076814522033)

33 Ribe AR, Laursen TM, Sandbaek A, Charles M, Nordentoft M $\&$ Vestergaard M. Long-term mortality of persons with severe mental illness and diabetes: a population-based cohort study in Denmark. Psychological Medicine 201444 3097-3107. (doi:10.1017/ S0033291714000634)

34 McCarthy JF, Ilgen MA, Austin K, Blow FC \& Katz IR. Associations between body mass index and suicide in the veterans affairs health system. Obesity 201422 269-276. (doi:10.1002/oby.20422)

35 Coleman SM, Katon W, Lin E \& Von Korff M. Depression and death in diabetes; 10-year follow-up of all-cause and cause-specific mortality in a diabetic cohort. Psychosomatics 201354 428-436. (doi:10.1016/j. psym.2013.02.015)

36 Cooper MN, de Klerk NH, Jones TW \& Davis EA. Clinical and demographic risk factors associated with mortality during early adulthood in a population-based cohort of childhood-onset type 1 diabetes. Diabetic Medicine 201431 1550-1558. (doi:10.1111/ dme.12522)

37 Morimoto A, Onda Y, Nishimura R, Sano H, Utsunomiya K \& Tajima N. Cause-specific mortality trends in a nationwide population-based cohort of childhood-onset type 1 diabetes in Japan during 35 years of 
follow-up: the DERI Mortality Study. Diabetologia 201356 2171-2175. (doi:10.1007/s00125-013-3001-2)

38 Gao S, Juhaeri J, Reshef S \& Dai WS. Association between body mass index and suicide, and suicide attempt among British adults: the health improvement network database. Obesity 201321 E334-E342. (doi:10.1002/oby.20143)

39 Ahola AJ, Harjutsalo V, Saraheimo M, Forsblom C \& Groop PH. Purchase of antidepressant agents by patients with type 1 diabetes is associated with increased mortality rates in women but not in men. Diabetologia 201255 73-79. (doi:10.1007/s00125-011-2347-6)

40 Batty GD, Kivimaki M, Park IS \& Jee SH. Diabetes and raised blood glucose as risk factors for future suicide: cohort study of 1234927 Korean men and women. Journal of Epidemiology and Community Health 201266 650-652. (doi:10.1136/jech-2011-200464)

41 Campbell PT, Newton CC, Patel AV, Jacobs EJ \& Gapstur SM. Diabetes and cause-specific mortality in a prospective cohort of one million U.S. adults. Diabetes Care 201235 1835-1844. (doi:10.2337/dc12-0002)

42 Harjutsalo V, Forsblom C \& Groop PH. Time trends in mortality in patients with type 1 diabetes: nationwide population based cohort study. BMJ 2011343 d5364. (doi:10.1136/bmj.d5364)

43 Torn C, Ingemansson S, Lindblad U \& Gudbjornsdottir S. Excess mortality in middle-aged men with diabetes aged 15-34 years at diagnosis. Acta Diabetologica 201148 197-202. (doi:10.1007/s00592011-0272-2)

44 Secrest AM, Becker DJ, Kelsey SF, Laporte RE \& Orchard TJ. Causespecific mortality trends in a large population-based cohort with long-standing childhood-onset type 1 diabetes. Diabetes 201059 3216-3222. (doi:10.2337/db10-0862)

45 Lin EH, Heckbert SR, Rutter CM, Katon WJ, Ciechanowski P, Ludman EJ, Oliver M, Young BA, McCulloch DK \& Von Korff M. Depression and increased mortality in diabetes: unexpected causes of death. Annals of Family Medicine 20097 414-421. (doi:10.1370/afm.998)

$46 \mathrm{Wu}$ MC, Lee WJ, Tschen SM, Lin SY, Lee IT, Jeng CY, Tseng LN, Liu YM, Chen BY \& Sheu WH. Predictors of mortality in hospitalized diabetic patients: A 7-year prospective study. Diabetes Research and Clinical Practice 200880 449-454. (doi:10.1016/j. diabres.2007.11.020)

47 Feltbower RG, Bodansky HJ, Patterson CC, Parslow RC, Stephenson $\mathrm{CR}$, Reynolds C \& McKinney PA. Acute complications and drug misuse are important causes of death for children and young adults with type 1 diabetes: results from the Yorkshire Register of diabetes in children and young adults. Diabetes Care 200831 922-926. (doi:10.2337/dc07-2029)

48 Patterson CC, Dahlquist G, Harjutsalo V, Joner G, Feltbower RG Svensson J, Schober E, Gyurus E, Castell C, Urbonaite B et al. Early mortality in EURODIAB population-based cohorts of type 1 diabetes diagnosed in childhood since 1989. Diabetologia 200750 2439-2442. (doi:10.1007/s00125-007-0824-8)

49 Bogner HR, Morales KH, Post EP \& Bruce ML. Diabetes, depression, and death: a randomized controlled trial of a depression treatment program for older adults based in primary care (PROSPECT). Diabetes Care 200730 3005-3010. (doi:10.2337/dc07-0974)

50 Skrivarhaug T, Bangstad HJ, Stene LC, Sandvik L, Hanssen KF \& Joner G. Long-term mortality in a nationwide cohort of childhood-onset type 1 diabetic patients in Norway. Diabetologia 200649 298-305. (doi:10.1007/s00125-005-0082-6)

51 Waernbaum I, Blohme G, Ostman J, Sundkvist G, Eriksson JW, Arnqvist HJ, Bolinder J \& Nystrom L. Excess mortality in incident cases of diabetes mellitus aged 15 to 34 years at diagnosis: a population-based study (DISS) in Sweden. Diabetologia 200649 653-659. (doi:10.1007/s00125-005-0135-x)

52 Dahlquist G \& Kallen B. Mortality in childhood-onset type 1 diabetes: a population-based study. Diabetes Care 200528 2384-2387. (doi:10.2337/diacare.28.10.2384)

53 Gnavi R, Petrelli A, Demaria M, Spadea T, Carta Q \& Costa G. Mortality and educational level among diabetic and non-diabetic population in the Turin Longitudinal Study: a 9-year follow-up. International Journal of Epidemiology 200433 864-871. (doi:10.1093/ ije/dyh089)

54 Tseng CH. Mortality and causes of death in a national sample of diabetic patients in Taiwan. Diabetes Care 200427 1605-1609. (doi:10.2337/diacare.27.7.1605)

55 Muhlhauser I, Sawicki PT, Blank M, Overmann H, Richter B \& Berger M. Reliability of causes of death in persons with Type I diabetes. Diabetologia 200245 1490-1497. (doi:10.1007/s00125-002-0957-8)

56 Wibell L, Nystrom L, Ostman J, Arnqvist H, Blohme G, Lithner F, Littorin B \& Sundkvist G. Increased mortality in diabetes during the first 10 years of the disease. A population-based study (DISS) in Swedish adults 15-34 years old at diagnosis. Journal of Internal Medicine 2001249 263-270. (doi:10.1046/j.1365-2796.2001.00802.x)

$57 \mathrm{Gu} \mathrm{K}$, Cowie CC \& Harris MI. Mortality in adults with and without diabetes in a national cohort of the U.S. population, 1971-1993. Diabetes Care 199821 1138-1145. (doi:10.2337/diacare.21.7.1138)

58 Warner DP, McKinney PA, Law GR \& Bodansky HJ. Mortality and diabetes from a population based register in Yorkshire 1978-93. Archives of Disease in Childhood 199878 435-438. (doi:10.1136/ adc.78.5.435)

59 Bourdel-Marchasson I, Dubroca B, Decamps A, Richard-Harston S, Emeriau JP \& Dartigues JF. Five-year mortality in elderly French subjects from the PAQUID epidemiologival survey: the burden of diabetes. Diabetic Medicine 199815 830-835. (doi:10.1002/(SICI)10969136(199810) 15:10<830::AID-DIA683>3.0.CO;2-3)

60 Koskinen SV, Reunanen AR, Martelin TP \& Valkonen T. Mortality in a large population-based cohort of patients with drug-treated diabetes mellitus. American Journal of Public Health $1998 \mathbf{8 8} 765-770$. (doi:10.2105/AJPH.88.5.765)

61 Schober E, Schneider U, Friedl HP \& Unsinn K. Early mortality in childhood diabetes in Austria - a population based cohort study. European Journal of Pediatrics 1997156 15-17. (doi:10.1007/ s004310050543)

62 Ingberg CM, Palmer M, Aman J \& Larsson S. Social consequences of insulin-dependent diabetes mellitus are limited: a populationbased comparison of young adult patients vs healthy controls. Diabetic Medicine 199613 729-733. (doi:10.1002/(SICI)10969136(199608)13:8<729::AID-DIA147>3.0.CO;2-A)

63 Swerdlow AJ \& Jones ME. Mortality during 25 years of follow-up of a cohort with diabetes. International Journal of Epidemiology 199625 1250-1261. (doi:10.1093/ije/25.6.1250)

64 McNally PG, Raymond NT, Burden ML, Burton PR, Botha JL, Swift PG, Burden AC \& Hearnshaw JR. Trends in mortality of childhood-onset insulin-dependent diabetes mellitus in Leicestershire: 1940-1991. Diabetic Medicine 199512 961-966. (doi:10.1111/j.1464-5491.1995. tb00406.x)

65 Sartor G \& Dahlquist G. Short-term mortality in childhood onset insulin-dependent diabetes mellitus: a high frequency of unexpected deaths in bed. Diabetic Medicine 199512 607-611. (doi:10.1111/j.1464-5491.1995.tb00550.x)

66 Hanis CL, Chu HH, Lawson K, Hewett-Emmett D, Barton SA, Schull WJ \& Garcia CA. Mortality of Mexican Americans with NIDDM. Retinopathy and other predictors in Starr County, Texas. Diabetes Care 199316 82-89. (doi:10.2337/diacare.16.1.82)

67 Nystrom L, Ostman J, Wall S \& Wibell L. Mortality of all incident cases of diabetes mellitus in Sweden diagnosed 1983-1987 at age 15-34 years. Diabetes Incidence Study in Sweden (DISS) Group. Diabetic Medicine 19929 422-427. (doi:10.1111/j.1464-5491.1992. tb01811.x)

68 Botha JL, Parker H, Raymond NT \& Swift PG. Diabetes diagnosed before the age of 2 years: mortality in a British cohort 8-17 years after onset. International Journal of Epidemiology 199221 1132-1137. (doi:10.1093/ije/21.6.1132)

69 Laing SP, Jones ME, Swerdlow AJ, Burden AC \& Gatling W. Psychosocial and socioeconomic risk factors for premature death in 
young people with type 1 diabetes. Diabetes Care 200528 1618-1623. (doi:10.2337/diacare.28.7.1618)

70 Moss SE, Klein R \& Klein BE. Cause-specific mortality in a populationbased study of diabetes. American Journal of Public Health 199181 1158-1162. (doi:10.2105/AJPH.81.9.1158)

71 Joner G \& Patrick S. The mortality of children with type 1 (insulindependent) diabetes mellitus in Norway, 1973-1988. Diabetologia 199134 29-32. (doi:10.1007/BF00404021)

72 Bild D, Geiss LS, Teutsch SM, Gabella B, Hudspeth BA, Schubert RM, Gollmar CW, Kaplan DJ, Connell FA \& Will JC. Sentinel health events surveillance in diabetes. Deaths among persons under age 45 with diabetes. Journal of Clinical Epidemiology 1988 41 999-1006. (doi:10.1016/0895-4356(88)90039-X)

73 Shibata M, Kishi T \& Iwata H. Clinical study of complications in dialyzed diabetics. Tohoku Journal of Experimental Medicine 1983141 (Supplement) 417-425. (doi:10.1620/tjem.141.Suppl_417)

74 Kessler, II. Mortality experience of diabetic patients. A twenty-sixyear follow-up study. American Journal of Medicine 197151 715-724. (doi:10.1016/0002-9343(71)90299-3)

75 MacGregor M. Juvenile diabetics growing up. Lancet $19771944-945$. (doi:10.1016/S0140-6736(77)92236-X)

76 Wright AK, Kontopantelis E, Emsley R, Buchan I, Sattar N, Rutter MK $\&$ Ashcroft DM. Life expectancy and cause-specific mortality in type 2 diabetes: a population-based cohort study quantifying relationships in ethnic subgroups. Diabetes Care 201740 338-345. (doi:10.2337/ dc16-1616)

77 Tseng CH. Factors associated with cancer- and non-cancer-related deaths among Taiwanese patients with diabetes after 17 years of follow-up. PLoS ONE 201611 e0147916. (doi:10.1371/journal. pone.0147916)

78 Nathan DM. Diabetes: advances in diagnosis and treatment. JAMA 2015314 1052-1062. (doi:10.1001/jama.2015.9536)

79 Bolton JM, Gunnell D \& Turecki G. Suicide risk assessment and intervention in people with mental illness. BMJ $2015 \mathbf{3 5 1} \mathrm{h} 4978$. (doi:10.1136/bmj.h4978)

80 Holt RI \& Mitchell AJ. Diabetes mellitus and severe mental illness: mechanisms and clinical implications. Nature Reviews Endocrinology 201511 79-89. (doi:10.1038/nrendo.2014.203)

81 Huang CJ, Wang SY, Lee MH \& Chiu HC. Prevalence and incidence of mental illness in diabetes: a national population-based cohort study. Diabetes Research and Clinical Practice 201193 106-114. (doi:10.1016/j.diabres.2011.03.032)

82 Chwastiak LA, Freudenreich O, Tek C, McKibbin C, Han J, McCarron $\mathrm{R} \&$ Wisse B. Clinical management of comorbid diabetes and psychotic disorders. Lancet Psychiatry 20152 465-476. (doi:10.1016/ S2215-0366(15)00105-4)

83 Snoek FJ, Bremmer MA \& Hermanns N. Constructs of depression and distress in diabetes: time for an appraisal. Lancet Diabetes and Endocrinology 20153 450-460. (doi:10.1016/S2213-8587(15)00135-7)

84 Thombs BD. Routine depression screening for patients with diabetes. JAMA 2014312 2412-2413. (doi:10.1001/jama.2014.14771)

85 Fuhr DC, Calvert C, Ronsmans C, Chandra PS, Sikander S, De Silva MJ \& Patel V. Contribution of suicide and injuries to pregnancy-related mortality in low-income and middle-income countries: a systematic review and meta-analysis. Lancet Psychiatry $20141213-225$. (doi:10.1016/S2215-0366(14)70282-2)

Received 20 November 2016

Revised version received 9 May 2017

Accepted 16 May 2017 